\title{
Closing the gap on lower cost air quality monitoring: machine learning calibration models to improve low-cost sensor performance
}

Naomi Zimmerman ${ }^{1}$, Albert A. Presto ${ }^{1}$, Sriniwasa P.N. Kumar ${ }^{1}$, Jason Gu$^{2}$, Aliaksei Hauryliuk ${ }^{1}$, Ellis S. Robinson $^{1}$, Allen L. Robinson ${ }^{1}$, R. Subramanian ${ }^{1}$

$5 \quad{ }^{1}$ Center for Atmospheric Particle Studies, Carnegie Mellon University, Pittsburgh, 15213, USA

${ }^{2}$ Sensevere LLC, Pittsburgh, 15222, USA

Correspondence to: R. Subramanian (subu@cmu.edu)

\section{Supplemental.}
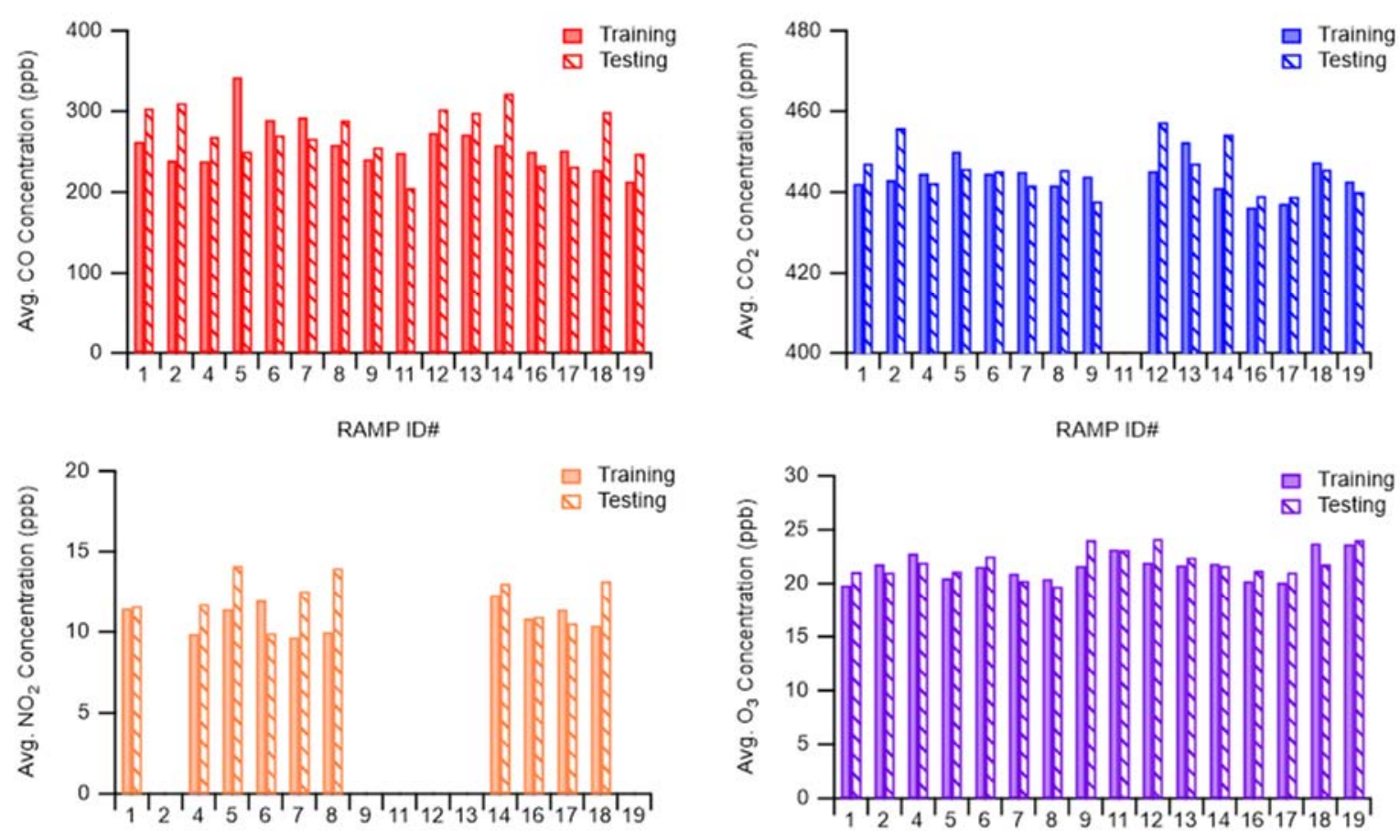

RAMP ID\#

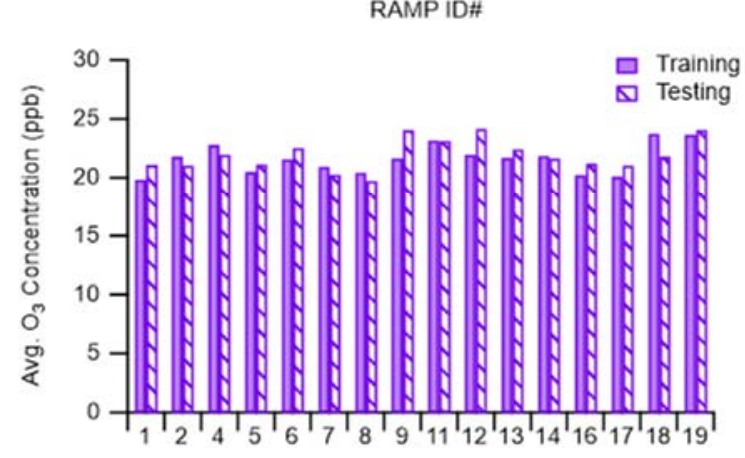

RAMP ID\#

Figure S1. Average reference monitor concentrations during training and testing windows for each RAMP 

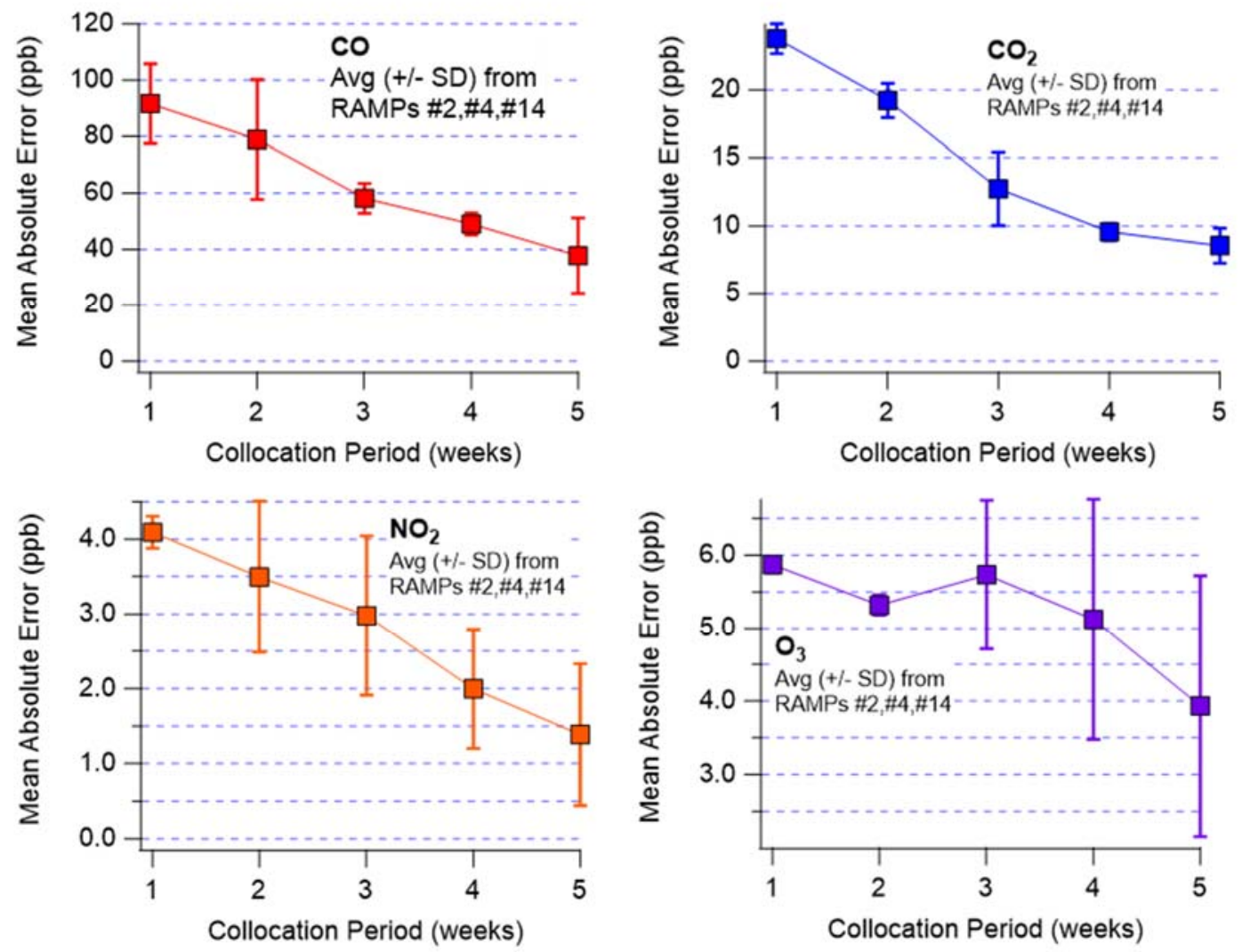

Figure S2: Choosing collocation length for training. Optimization assessed on a subset of three RAMPs (RAMP \#2, \#4, and \#14). Ultimately a 4-week collocation period was chosen as being the best across all four species.

Table S1: Change in model performance if one consecutive 4-week colocation at the beginning of the study is conducted vs spacing out training data throughout the study in 8 half week increments.

Impact of using one consecutive four week training window vs. distributed half week colocations

\begin{tabular}{|c|c|c|c|c|}
\hline Metric & $\mathrm{CO}$ & $\mathrm{CO}_{2}$ & $\mathrm{NO}_{2}$ & $\mathbf{O}_{3}$ \\
\hline RMSE & $+11.9 \mathrm{ppb}$ & $+3.2 \mathrm{ppm}$ & $+0.4 \mathrm{ppb}$ & $+1.6 \mathrm{ppb}$ \\
\hline MAE & $+12.1 \mathrm{ppb}$ & $+1.8 \mathrm{ppm}$ & $+0.4 \mathrm{ppb}$ & $+1.6 \mathrm{ppb}$ \\
\hline Pearson r & -0.01 & -0.03 & -0.08 & -0.05 \\
\hline
\end{tabular}


Table S2. Metrics used for comparing sensor data. $M$ indicates a value measured by one of the sensors participating in the experiment and $\mathrm{O}$ indicates the observations from the reference measurements.

\begin{tabular}{|c|c|c|c|}
\hline Statistic & Abbrev. & Formula & Characteristics \\
\hline $\begin{array}{l}\text { Mean Bias } \\
\text { Error }\end{array}$ & $\mathrm{MBE}$ & $\mathrm{MBE}=\overline{\mathrm{M}}-\overline{\mathrm{O}}$ & $\begin{array}{l}\text { Estimation of the magnitude of differences (bias) } \\
\text { between sensors estimation and reference values } \\
\text { averaged over the whole sampling period }\end{array}$ \\
\hline $\begin{array}{l}\text { Mean } \\
\text { Absolute } \\
\text { Error }\end{array}$ & MAE & $\mathrm{MAE}=\frac{1}{\mathrm{n}} \sum_{i=1}^{n}\left|M_{i}-O_{i}\right|$ & $\begin{array}{l}\text { - Indicates the average of the magnitude of the errors. } \\
\text { - Sensitive to outliers. }\end{array}$ \\
\hline $\begin{array}{l}\text { Pearson } \\
\text { Correlation } \\
\text { Coefficient }\end{array}$ & $\mathrm{r}$ & $\mathrm{r}=\frac{\sum_{i=1}^{n}\left(M_{i}-\bar{M}\right)\left(O_{i}-\bar{O}\right)}{\sqrt{\sum_{i=1}^{n}\left(M_{i}-\bar{M}\right)^{2}\left(O_{i}-\bar{O}\right)^{2}}}$ & $\begin{array}{l}\text { Measures the strength and the direction of a linear } \\
\text { relationship between two variables. }\end{array}$ \\
\hline $\begin{array}{l}\text { Root Mean } \\
\text { Square Error }\end{array}$ & RMSE & $R M S E=\sqrt{\frac{1}{n}} \sum_{i=1}^{n}\left(M_{i}-O_{i}\right)^{2}$ & $\begin{array}{l}\text { - Magnitude of the error and retains the variable's unit } \\
\text { - Sensitive to extreme values and to outliers }\end{array}$ \\
\hline \multicolumn{4}{|l|}{ Centred Root } \\
\hline $\begin{array}{l}\text { Mean Square } \\
\text { Error }\end{array}$ & CRMSE & $C R M S E=\sqrt{R M S E^{2}-M B E^{2}}$ & $\begin{array}{l}\text { - RMSE corrected for bias } \\
\text { - Measure of random error }\end{array}$ \\
\hline
\end{tabular}


Plots of Goodness of Fit (Results from Training, Figures S3-S6)
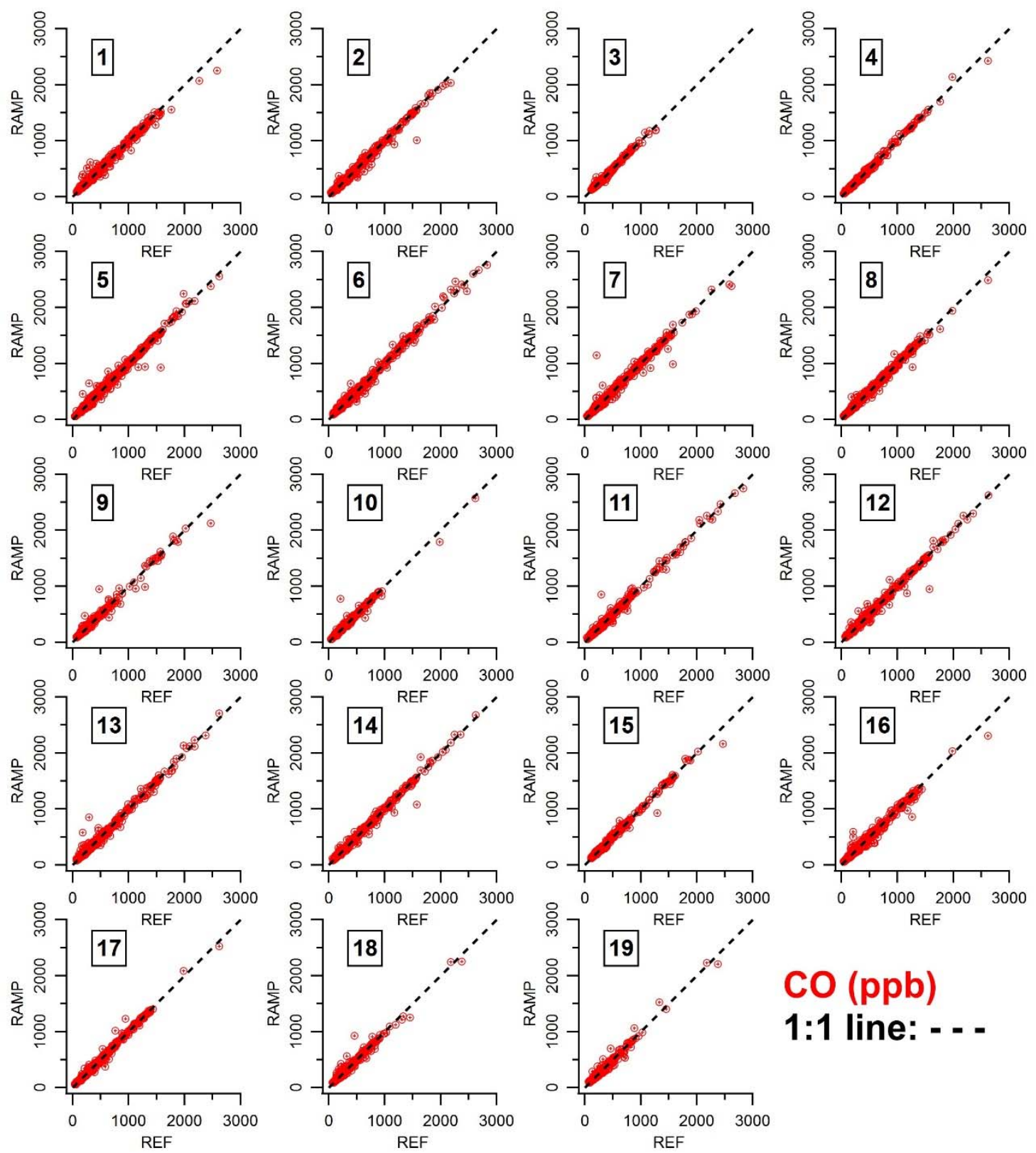

Figure S3: Goodness of fit on training data across all 19 RAMPs for CO using random forests. 

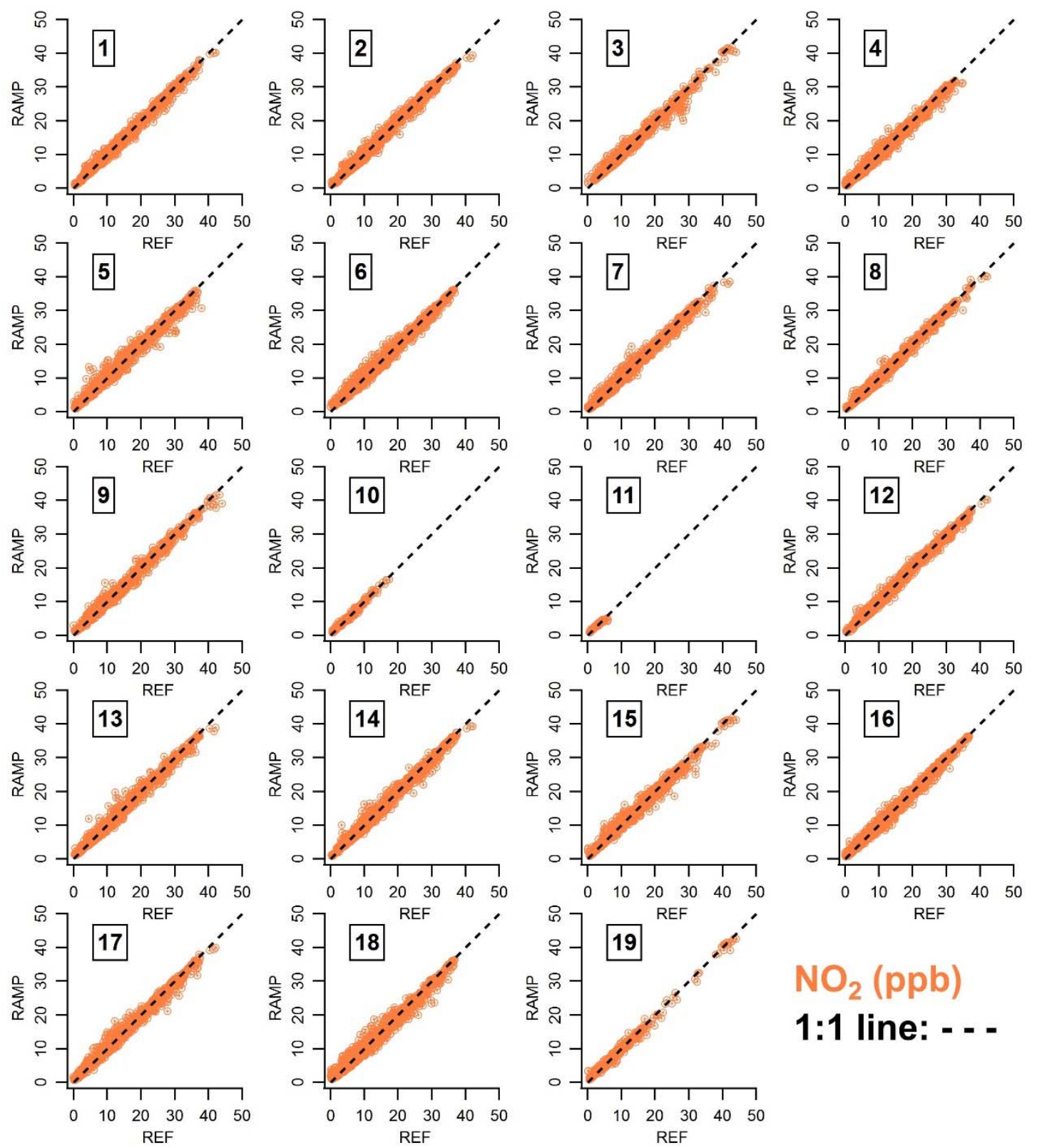

Figure S4: Goodness of fit on training data across all 19 RAMPs for $\mathrm{NO}_{2}$ using random forests. 

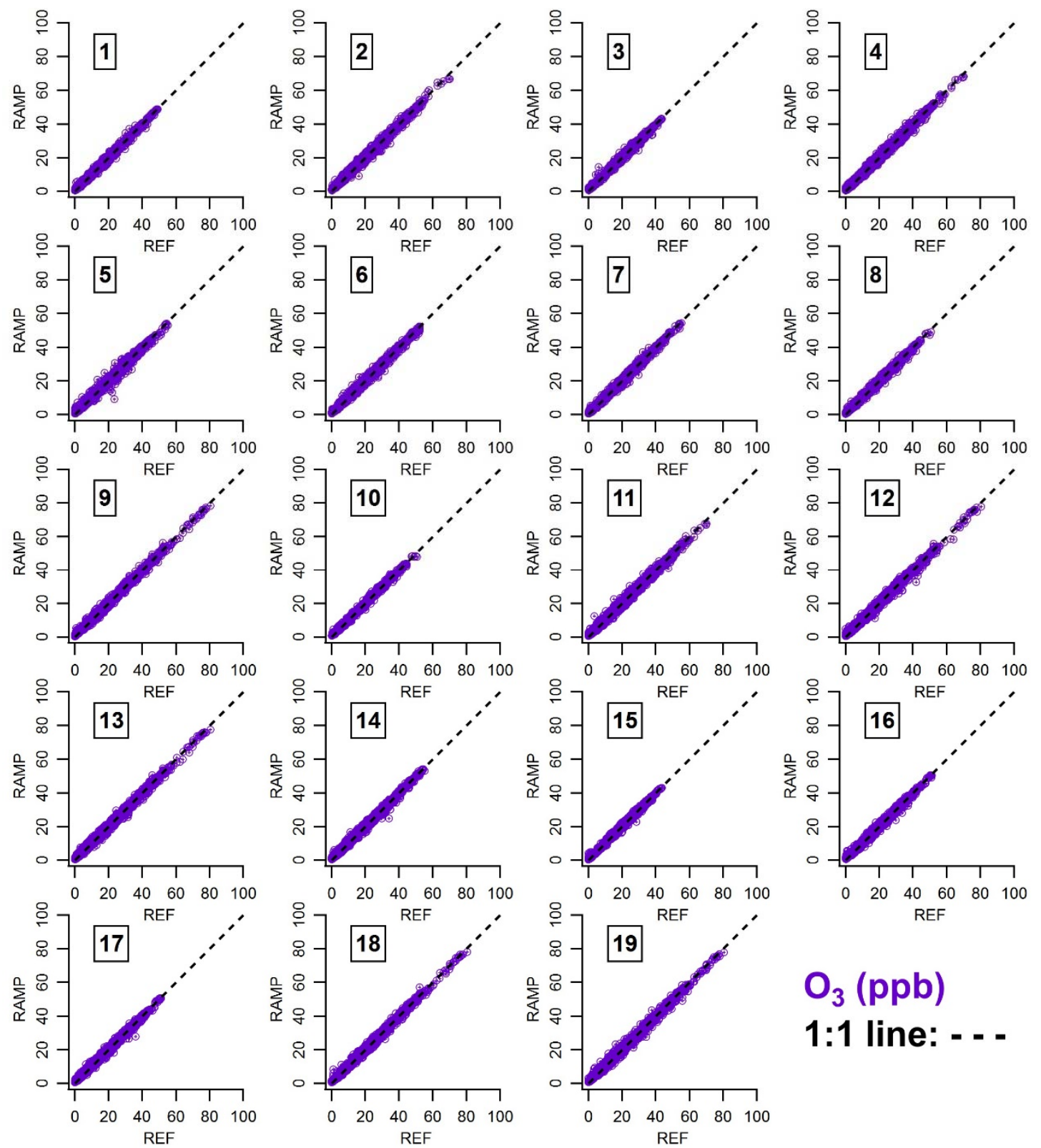

Figure S5: Goodness of fit on training data across all 19 RAMPs for $\mathrm{O}_{3}$ using random forests. 

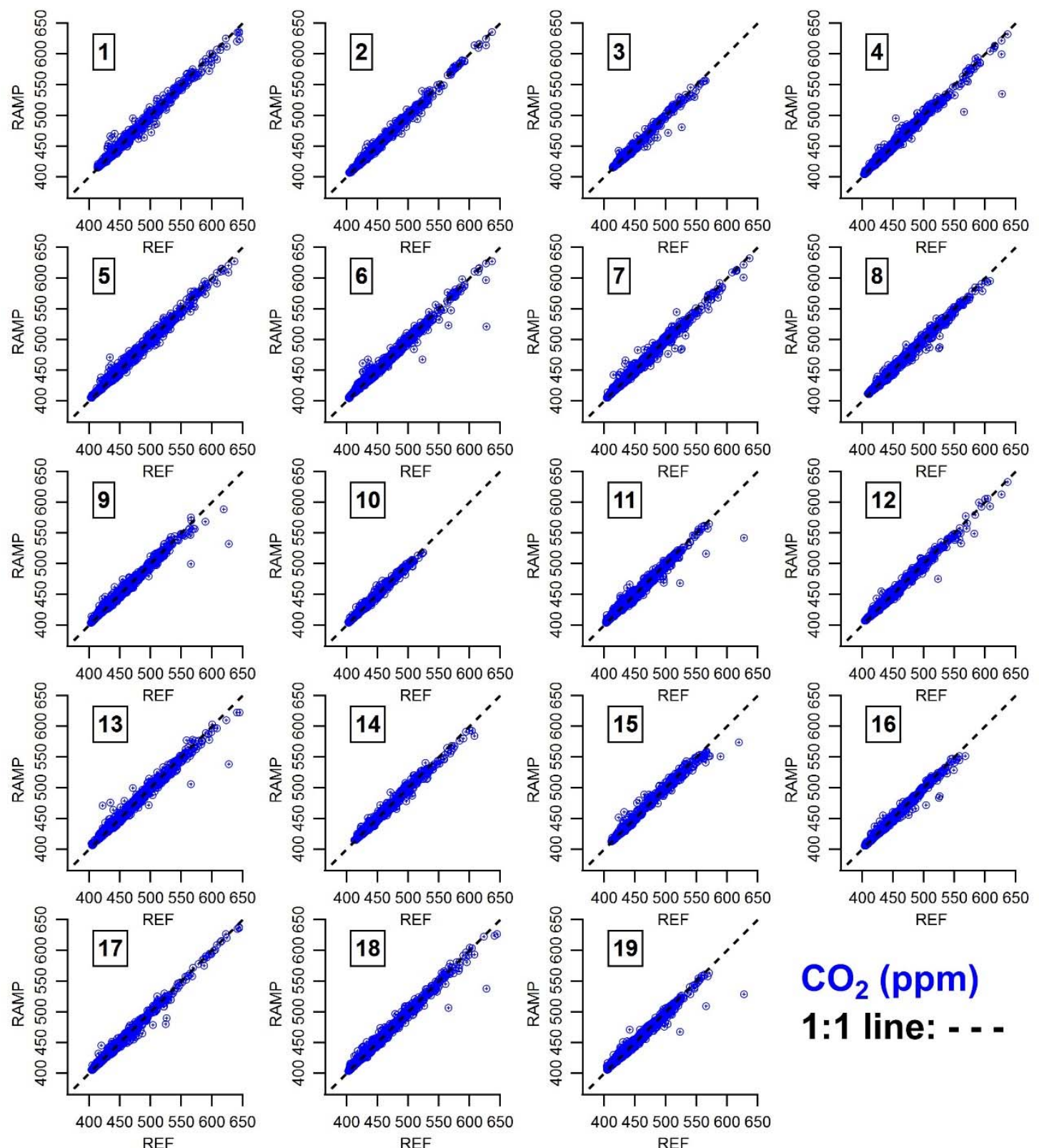

REF

$\mathrm{CO}_{2}$ (ppm)

\section{1:1 line: - - -}

Figure S6: Goodness of fit on training data across all 19 RAMPs for $\mathrm{CO}_{2}$ using random forests. 
Plots of Random Forest Performance by RAMP (Results from Testing, Figures S7-S10)
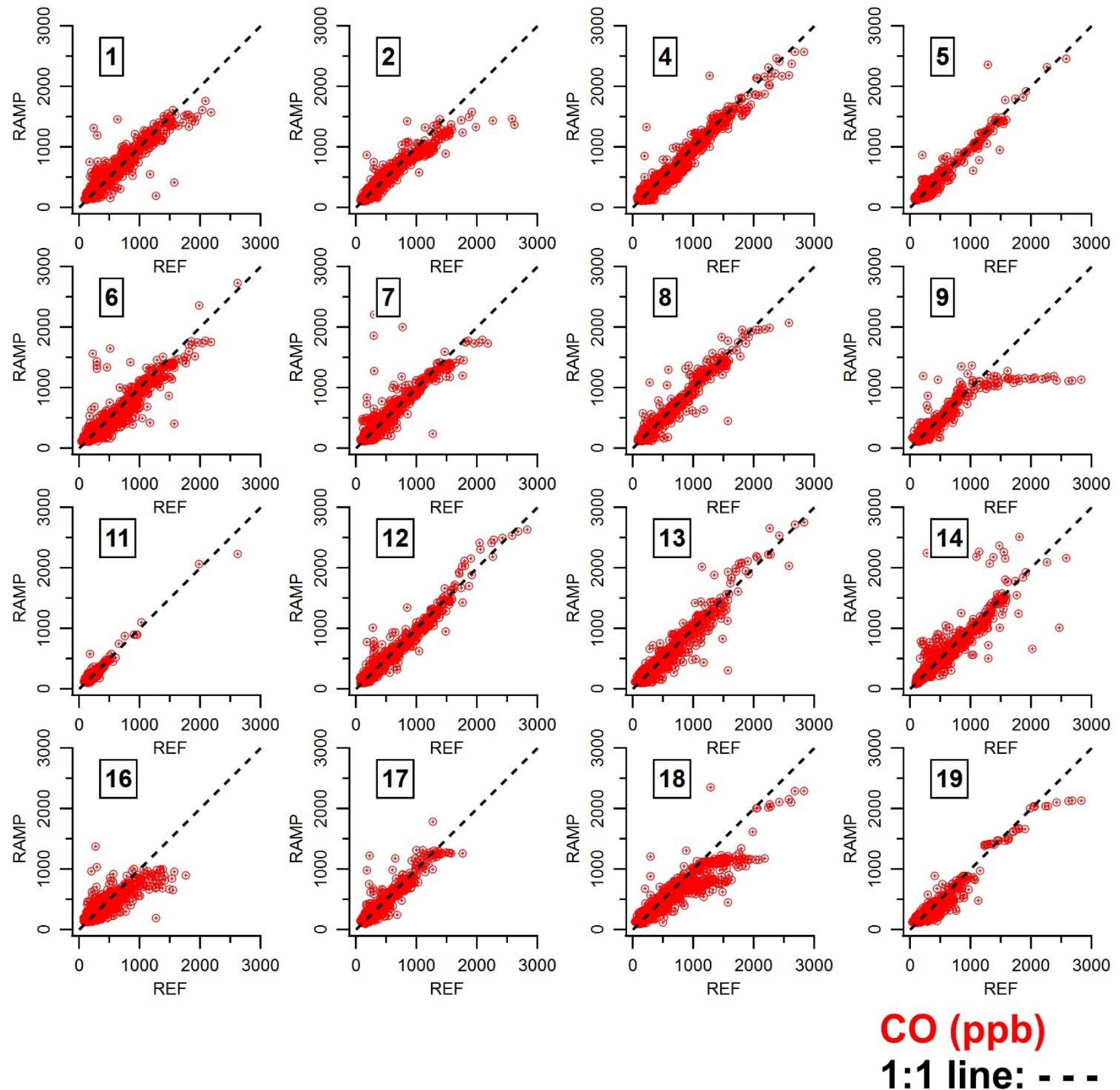

Figure S7: Model performance on testing data across 16 RAMPs for CO using random forests. 

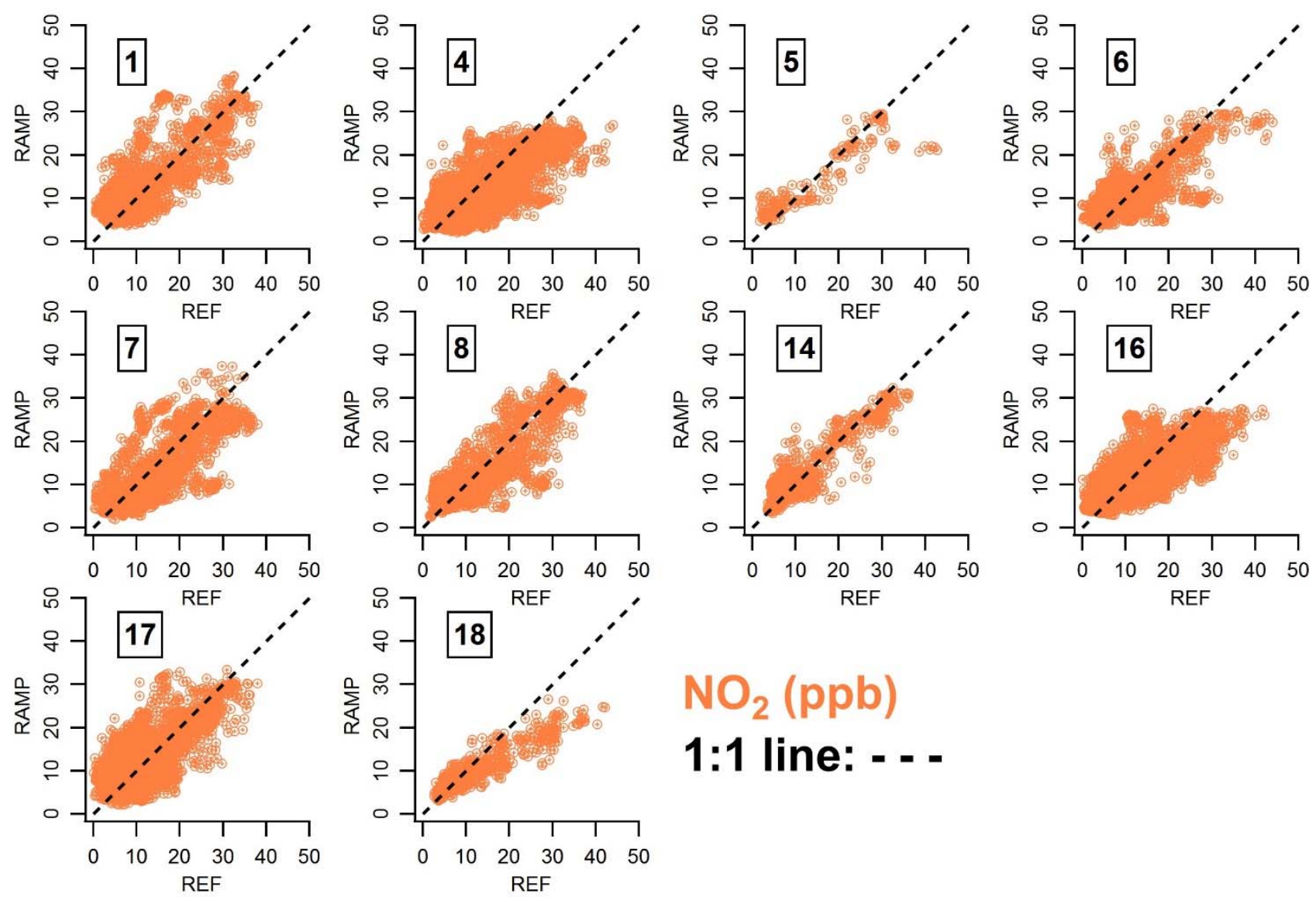

Figure S8: Model performance on testing data across 10 RAMPs for $\mathrm{NO}_{2}$ using random forests. 

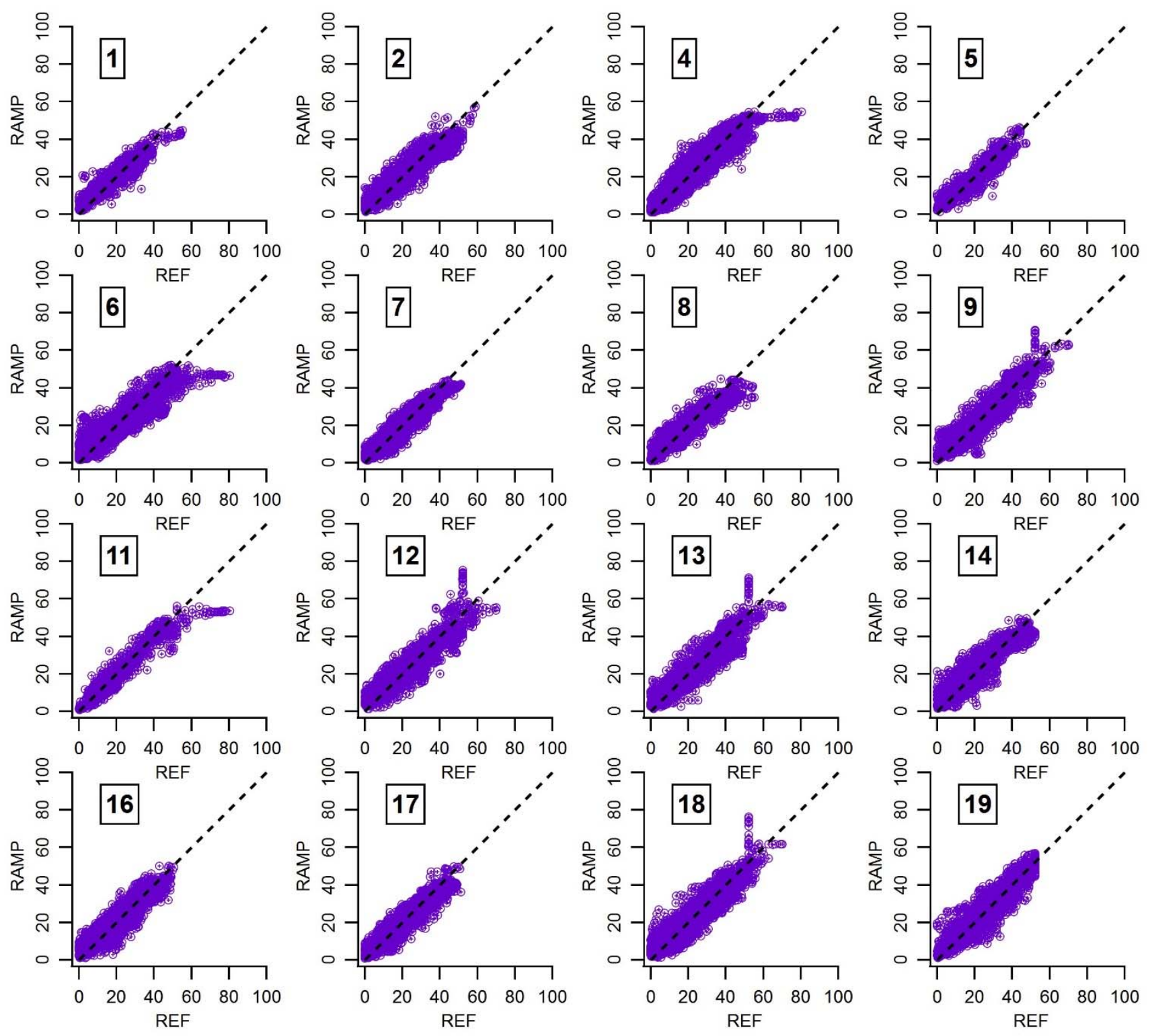

$\mathrm{O}_{3}$ (ppb)

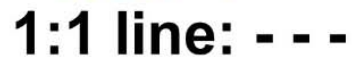

Figure S9: Model performance on testing data across 16 RAMPs for $\mathrm{O}_{3}$ using random forests. 

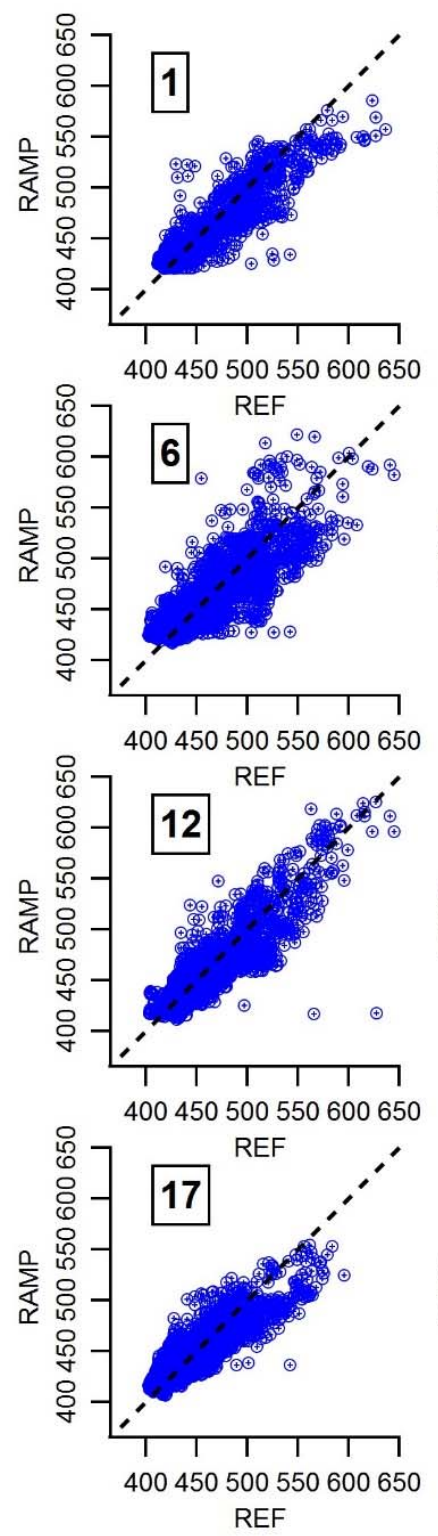
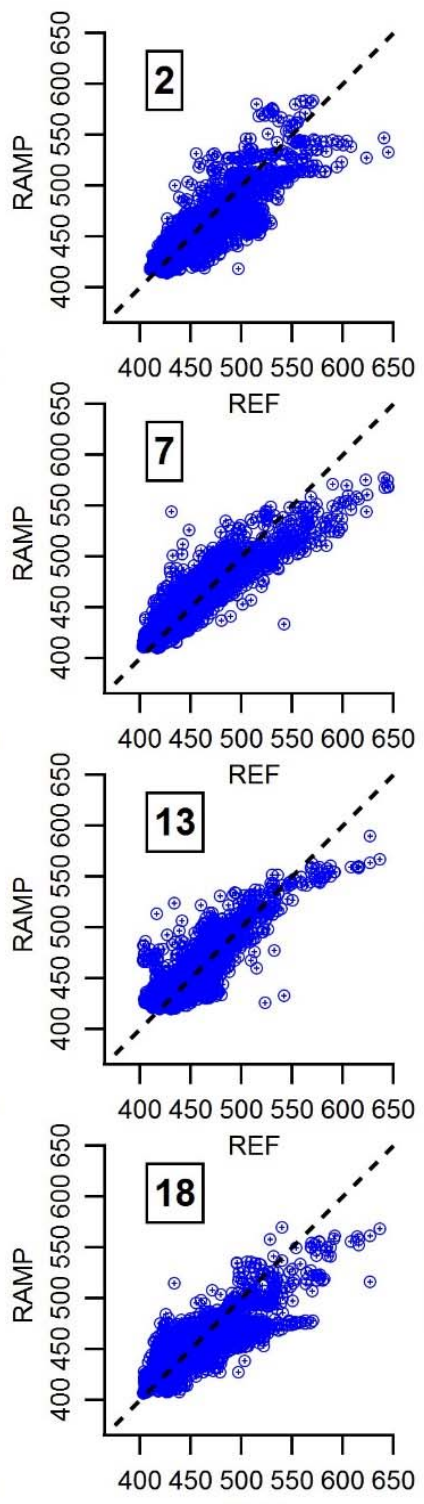

REF
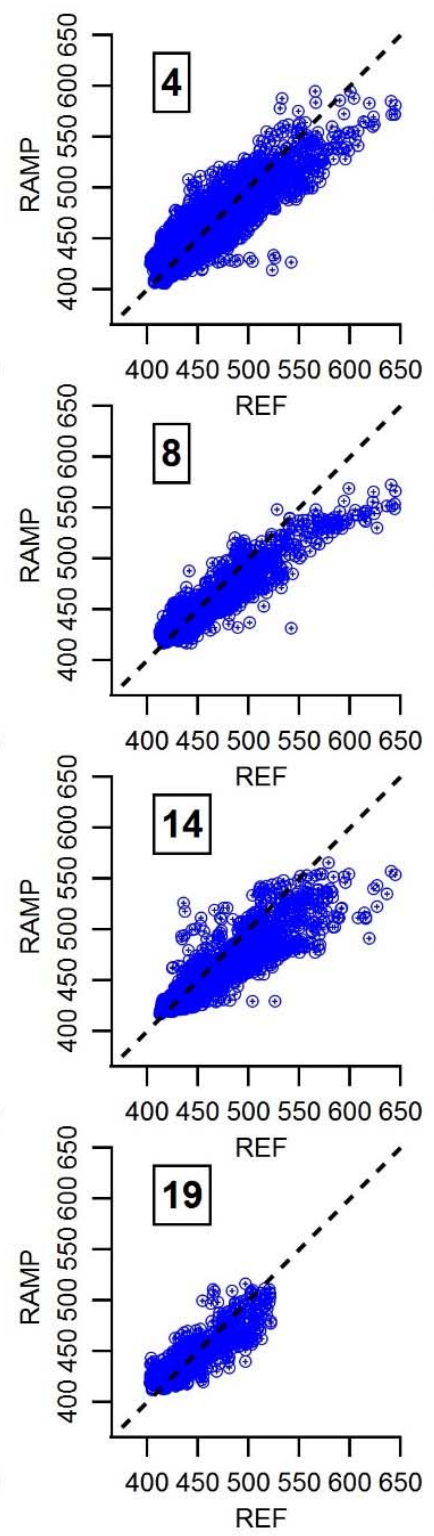
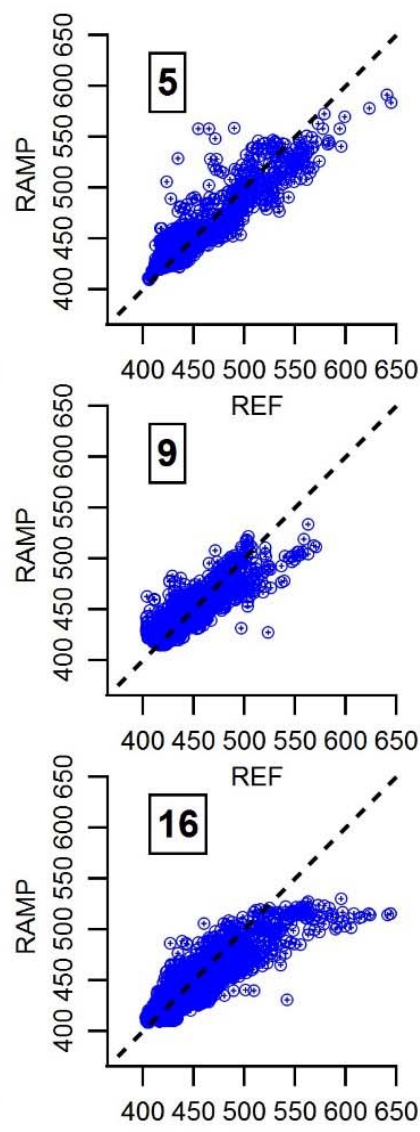

REF

\section{$\mathrm{CO}_{2}$ (ppm)}

1:1 line: - . -

Figure S10: Model performance on testing data across $15 \mathrm{RAMPs}$ for $\mathrm{CO}_{2}$ using random forests. 


\section{US EPA Air Sensor Guidebook Precision and Bias Estimators:}

\section{Precision:}

5 The precision estimator (CV) is the upper bound of the $90 \%$ confidence interval on the coefficient of variation.

$$
C V=\sqrt{\frac{n \cdot \sum_{i=1}^{n} d_{i}^{2}-\left(\sum_{i=1}^{n} d_{i}\right)^{2}}{n(n-1)} \cdot \sqrt{\frac{n-1}{\chi_{(0.1, n-1)}^{2}}}}
$$

Where $\mathrm{n}$ is the number of data points, $\chi_{(0.1, n-1)}^{2}$ is the $10^{\text {th }}$ percentile of a chi-squared distribution with $\mathrm{n}-1$ degrees of 10 freedom, and $\mathrm{d}_{\mathrm{i}}$ is equal to:

$$
\mathbf{d}_{\mathbf{i}}=\frac{\mathbf{R A M P}-\text { reference }}{\text { reference }} \cdot \mathbf{1 0 0} \%
$$

\section{Bias:}

15

The bias estimator is the upper bound of the $95 \%$ confidence interval on the mean absolute value of the percent difference between the RAMPs and the reference monitor.

$$
|B i a s|=A B+t_{0.95, n-1} \cdot \frac{A S}{\sqrt{n}}
$$

Where $t_{0.95, n-1}$ is the $95^{\text {th }}$ quartile of a t-distibution with $n-1$ degrees of freedom and $A B$ is the mean of the absolute values 20 of the $\mathrm{d}_{\mathrm{i}}$ 's.

$$
A B=\frac{1}{n} \sum_{i=1}^{n}\left|d_{i}\right|
$$

And AS is the standard deviation of the absolute value of the $\mathrm{d}_{\mathrm{i}}$ 's:

$$
\mathbf{A S}=\sqrt{\frac{\mathbf{n} \cdot \sum_{\mathrm{i}=1}^{\mathrm{n}}\left|\boldsymbol{d}_{i}\right|^{2}-\left(\sum_{\mathrm{i}=1}^{\mathrm{n}}\left|\boldsymbol{d}_{\boldsymbol{i}}\right|\right)^{2}}{\mathbf{n}(\mathbf{n}-\mathbf{1})}}
$$

